\title{
Desafios da predição algorítmica na tutela jurídica dos contratos eletrônicos de consumo
}

\section{Challenges of algorithmic prediction in the legal protection of electronic consumer contracts}

\author{
José Luiz de Moura Faleiros Júnior*
}

Arthur Pinheiro Basan ${ }^{* *}$

\begin{abstract}
REFERÊNCIA
FALEIROS JÚNIOR, José Luiz de Moura; BASAN, Arthur Pinheiro. Desafios da predição algorítmica na tutela jurídica dos contratos eletrônicos de consumo. Revista da Faculdade de Direito da UFRGS, Porto Alegre, n. 44, p. 131-153, dez. 2020. DOI: https://doi.org/10.22456/0104-6594.95264.
\end{abstract}

\begin{abstract}
RESUMO
O presente trabalho visa verificar a utilização, por empresas que exploram atividades de comércio eletrônico, das práticas de geopricing e de geoblocking, demonstrando como essas práticas de mercado violam os direitos dos consumidores. Para tanto, será analisado o caso concreto em que o Departamento de Proteção e Defesa do Consumidor (DPDC), órgão do Ministério da Justiça, condenou a empresa "Decolar.com" ao pagamento de multa por diferenciação de preço de acomodações e negativa de oferta de vagas, de acordo com a localização geográfica do consumidor que utilizava a plataforma para a pesquisa. Trabalha-se com a hipótese de que a incidência da nova Lei Geral de Proteção de Dados Pessoais (Lei 13.709/2018), em especial com relação aos metaparâmetros dos arts 46 a 51, dá indícios de se tornar ferramenta efetiva para a prevenção de ilícitos e, consequentemente, para a promoção da tutela dos ciberconsumidores. A pesquisa utilizará o método de abordagem indutivo, investigando os fatos ocorridos no caso da empresa "Decolar.com" para evidenciar a problemática da tecnologia sobre o Direito. Além disso, o trabalho promoverá a análise bibliográficodoutrinária para, logo em seguida, apresentar as considerações finais, das quais se procurará extrair uma compreensão mais assertiva quanto à problemática explicitada.
\end{abstract}

\section{PALAVRAS-CHAVE}

Geo-pricing; Geo-blocking. Práticas abusivas. Comércio eletrônico. Dados pessoais.

\begin{abstract}
This article aims to verify the use, by companies that explore e-commerce activities, of geopricing and geoblocking, demonstrating how these market practices violate the rights of consumers. Therefore, it will be analyzed the case in which the Brazilian Department of Consumer Protection and Guardianship, an organ of the Ministry of Justice, fined the company "Decolar.com" for price differentiation and denial of offer in accommodation bookings according to the geographic location of the consumer who used the platform for the research. It is hypothesized that the incidence of the new General Personal Data Protection Law (Law No. 13.709/2018), in particular regarding the metaparameters of articles 46 to 51, shall become an effective tool for the prevention of such illicit acts and, consequently, for the promotion of cyber-consumer protection. The research will use an inductive approach method, investigating the facts that occurred in the case of the company "Decolar.com" to highlight the problem of technology intertwined with the law. In addition, the work will promote a bibliographic-doctrinal analysis and, then, present the final considerations, which will seek to extract a more assertive understanding of the problem.
\end{abstract}

\section{KEYWORDS}

Geo-pricing. Geo-blocking. Abusive practices. E-commerce. Personal data.

\footnotetext{
* Mestrando em Direito pela Universidade Federal de Uberlândia (UFU). Especialista em Direito Processual Civil, Direito Digital e Compliance pela Faculdade de Direito Prof. Damásio de Jesus (FDDJ). Graduado em Direito pela Universidade Federal de Uberlândia (UFU). Advogado.

** Doutorando em Direito pela Universidade do Vale do Rio do Sinos (UNISINOS). Mestre em Direito pela Universidade Federal de Uberlândia (UFU). Especialista em Direito Constitucional pela Faculdade de Direito Prof. Damásio de Jesus (FDDJ). Professor adjunto na Universidade de Rio Verde (UniRV).
} 


\section{SUMÁRIO}

1. Introdução. 2.Decisão administrativa que tratou do geopricing e do geoblocking frente à "Decolar.com". 3. A proibição de discriminação do consumidor como princípio básico do sistema jurídico brasileiro. 4. O comércio eletrônico e as novas práticas de discriminação no mercado. 5. Os metaparâmetros da Lei Geral de Proteção de Dados Pessoais (Lei 13.709/2018) na tutela do consumidor virtual. 6. Conclusão. Referências. Dados da publicação.

\section{INTRODUÇÃ̃o}

O presente trabalho tem como propósito analisar o caso concreto em que o Departamento de Proteção e Defesa do Consumidor (DPDC), órgão do Ministério da Justiça, condenou a empresa "Decolar.com" ao pagamento de multa por diferenciação de preço de acomodações e negativa de oferta de vagas, de acordo com a localização geográfica do consumidor. Tais práticas são denominadas pela doutrina como geopricing e geoblocking.

Assim, o presente texto busca, incialmente, expor o julgado que decidiu em desfavor da empresa "Decolar.com", para, em seguida, investigar se o ocorrido pode servir de parâmetro para a tutela dos direitos dos consumidores no comércio eletrônico em situações análogas.

Visando à melhor compreensão do tema, pretende-se demonstrar como essas práticas do mercado eletrônico configuram afrontas ao sistema de proteção dos consumidores, ao se enquadrarem, no Código de Defesa do Consumidor, como práticas abusivas. Para tanto, será feita uma breve abordagem dos princípios básicos das relações de consumo, passando, após, ao estudo mais específico acerca do dever de respeito às normas consumeristas, inclusive no âmbito do comércio eletrônico.

Adiante, no intuito de desenvolver um raciocínio de proteção e de combate a práticas abusivas no meio virtual, trabalhar-se-á com a hipótese de que a incidência da nova Lei Geral de Proteção de Dados Pessoais (Lei 13.709/2018), em especial com relação aos metaparâmetros dos arts. 46 a 51, será ferramenta efetiva para a prevenção de ilícitos desse jaez, por tutelar o tratamento dos dados pessoais coletados em rede.

Ao fim, partindo para considerações finais, apresentar-se-á a síntese do tema, questionando se a decisão em enfoque promoveu, efetivamente, a completa tutela dos direitos dos consumidores, exigida expressamente no artigo $5^{\circ}$, inciso XXXII, da Constituição da República. 


\section{DECISÃO ADMINISTRATIVA QUE TRATOU DO GEOPRICING E DO GEOBLOCKING FRENTE À "DECOLAR.COM"}

Em junho de 2018, foi amplamente divulgada a condeção da empresa "Decolar.com" por violação a direitos de seus consumidores. O caso teve início com a instauração de inquérito civil, pela $5^{\mathrm{a}}$ Promotoria de Justiça de Tutela Coletiva de Defesa do Consumidor e do Contribuinte da Capital, do Ministério Público do Estado do Rio de Janeiro, pelo labor dos Promotores de Justiça, Dr. Pedro Rubim Borges Fortes e Dr. Guilherme Magalhães Martins. ${ }^{1}$

Após a eclosão do caso, em decisão inédita no Brasil, o Departamento de Proteção e Defesa do Consumidor (DPDC) condenou a fornecedora supracitada, na esfera administrativa, ao pagamento de multa no valor de $\mathrm{R} \$ 7.500 .000,00$ (sete milhões e quinhentos mil reais) por diferenciação de preço de acomodações e negativa de oferta de vagas, quando existentes, de acordo com a localização geográfica do consumidor. Tais técnicas são conhecidas como geopricing e geoblocking, respectivamente. Conforme a decisão:

[A empresa foi] sancionada por conta da prática aqui apontada, qual seja, a diferenciação de preço de acomodações e negativa de oferta de vagas, quando existentes, de acordo com a localização geográfica do consumidor, sendo considerada uma prática abusiva e discriminatória, a empresa deve cessar imediatamente a prática, sob pena de suspensão da atividade, bem como a retirada do site do ar $[\ldots]^{2}$

Desse modo, logo após a supracitada condenação, a notícia foi amplamente divulgada pelos meios de comunicação ${ }^{3}$, forçando a empresa a se pronunciar publicamente. Em nota, defendeu-se alegando que opera em cada país por meio de sites locais e que estes não fazem nenhuma discriminação de preços com relação a consumidores nacionais ou estrangeiros.

Ademais, em relação aos preços desiguais evidenciados por usuários distintos, a empresa alegou que foram comparados mercados diferentes (no caso, da Argentina e do

\footnotetext{
${ }^{1}$ COSTA, Daiane. Decolar recebe pedido de reparação de R $\$ 57$ milhões por cobrar mais de brasileiros. $O$ Globo. 08 fev. 2018. Disponível em: https://oglobo.globo.com/economia/decolar-recebe-pedido-de-reparacaode-57-milhoes-por-cobrar-mais-de-brasileiros-22367398. Acesso em: 04 ago. 2019.

${ }^{2}$ BRASIL. Secretaria Nacional do Consumidor. Departamento Nacional de Proteção e Defesa do Consumidor. Despacho $n^{\circ}$ 299/2018. Decisão de Aplicação de Sanção Administrativa. Processo no 08012.002116/2016-21. Representada: Decolar.com Ltda. DOU. Diário Oficial da União. Publicado no DOU de 18 de junho 06 de 2018. ${ }^{3}$ Destaca-se que a notícia foi divulgada em diversos portais: VENTURA, Ivan. Decolar.com é multada em R\$ 7,5 milhões por desrespeito ao consumidor. Consumidor Moderno. 18 jun. 2018. Disponível em: https://www.consumidormoderno.com.br/2018/06/18/decolar-multada-milhoes-desrespeito-consumidor/. Acesso em: 11. jul 2019; MIOZZO, Júlia. Decolar é multada em R \$ 7,5 milhões por práticas abusivas contra consumidor. InfoMoney. 18 jun. 2018. Disponível em: https://www.infomoney.com.br/minhasfinancas/turismo/noticia/7479979/decolar-multada-milhoes-por-praticas-abusivas-contra-consumidor. Acesso em: 12 jul. 2019.
} 
Brasil), sujeitos a legislações e regulamentos também diversos. ${ }^{4}$ A fornecedora ainda alegou que atua como mera intermediadora entre os fornecedores e consumidores no que diz respeito à hospedagem, sendo esses fornecedores os reais responsáveis pela inclusão dos preços e disponibilidade de acomodações, insistindo, portanto, que não pratica o denonimnado geopricing.

Vale destacar que, no relatório que acompanha a decisão que condenou a "Decolar.com", o Departamento de Proteção e Defesa do Consumidor (DPDC) considerou que ao precificar, ou mesmo permitir que se precifique, o serviço de acomodação de acordo com a localização geográfica do consumidor, a fornecedora viola as práticas legais do mercado. Dito de outra maneira, segundo este relatório, nada justifica a ocorrência de preços diferentes com relação a serviços que são prestados no mesmo local e nas mesmas condições. Em verdade, nesta situação, qualquer consumidor que esteja disposto a pagar por esses serviços deveria ser cobrado na mesma quantia.

Ainda assim, no que se refere a não exibição da disponibilidade total de acomodações, a infração à ordem jurídica, conforme destacado na decisão administrativa, é ainda mais evidente. Segundo consta, a empresa não ofertava o serviço que não queria vender a determinado consumidor (no caso, um consumidor brasileiro), enquanto o oferecia a outro usuário (no caso, um consumidor argentino). Concluiu a decisão, assim, que o favorecimento (ou desfavorecimento), bem como a discriminação em razão da localização geográfica, ou por qualquer outra característica extrínseca ao ato comercial, causa desequilíbrio no mercado e nas relações de consumo, violando o sistema jurídico pátrio. ${ }^{5}$

O caso da "Decolar.com" representa a concretização de um dos maiores temores no que se refere à utilização indevida de dados pessoais, especialmente para fins de discriminação de consumidores a partir de implementos algorítmicos desprovidos do devido consentimento esclarecido e prévio.

\footnotetext{
${ }^{4}$ RIBEIRO, Luci. Decolar é multada em R \$ 7,5 milhões por práticas abusivas. Estadão. 18 jun. 2018. Disponível em: https://economia.estadao.com.br/noticias/negocios,decolar-e-multada-em-r-7-5-milhoes-por-praticasabusivas,70002354803. Acesso em 11 de jul. de 2019.

${ }^{5}$ BRASIL. Ministério da Justiça e Segurança Pública. Decolar.com é multada por prática de geo pricing e geo blocking. Disponível em: https://www.justica.gov.br/news/collective-nitf-content-51. Acesso em 11 jul. 2019.
} 


\section{A PROIBIÇÃO DE DISCRIMINAÇÃO DO CONSUMIDOR COMO PRINCÍPIO BÁSICO DO SISTEMA JURÍDICO BRASILEIRO}

Não há dúvidas de que "se o fenômeno informático é recente, a problemática dos direitos fundamentais é pensada há muito tempo" ${ }^{\circ} \mathrm{e}$, com o advento da Constituição da República de 1988, todo o sistema jurídico brasileiro foi submetido a uma verdadeira reformulação, visando à atribuição de coerência ao modelo de Estado democrático estabelecido. Foi esse também o caminho operado pelo direito privado, influenciado pela expansão dos direitos fundamentais ${ }^{7}$, em razão, inclusive, de expressa determinação constitucional. Adotou-se a defesa do consumidor como princípio fundamental, consagrando passo essencial para a consolidação do chamado "direito privado solidário". 8

Em verdade, analisando a lógica do mercado, que opera pelo código binário "lucro/não lucro", a proteção do consumidor se mostra como uma forma de superar as falhas do mercado, que expõe as pessoas ao risco de danos. ${ }^{9}$ Dito de outro modo, é a lei que cumpre a função de ordenar o mercado no afã de proteger as pessoas das práticas comerciais abusivas, garantindo o cumprimento efetivo do fundamento de tutela da pessoa humana, expresso na carta constitucional, mesmo dentro da lógica do direito privado, o que demonstra a eficácia horizontal das normas fundamentais. ${ }^{10}$

Despiciendo dizer que o Código de Defesa do Consumidor, em seu artigo inaugural, estebelece que sua finalidade é a proteção e defesa do consumidor, matéria de ordem pública e interesse social, ressaltando o artigo 170, inciso $\mathrm{V}$, da CF/88, o qual, expressamente, impõe ao legislador infraconstitucional a defesa do consumidor como princípio geral da atividade econômica, mas que cumpre função promocional dos direitos humanos. ${ }^{11}$ Noutras palavras,

\footnotetext{
${ }^{6}$ LIMBERGER, Têmis. Direito e informática: o desafio de proteger os direitos do cidadão. In: SARLET, Ingo Wolfgang (Org.). Direitos fundamentais, informática e comunicação: algumas aproximações. Porto Alegre: Livraria do Advogado, 2007, p. 197.

${ }^{7}$ CANARIS, Claus-Wilhelm. Direitos fundamentais e direito privado. Tradução de Ingo Wolfgang Sarlet e Paulo Mota Pinto. Coimba: Almedina, 2003, passim.

${ }^{8}$ BENJAMIN, Antonio Herman V.; MARQUES, Claudia Lima; BESSA, Leonardo Roscoe. Manual de direito do consumidor. 7. ed. São Paulo: Revista dos Tribunais, 2016, p. 27.

${ }^{9}$ SANDEL, Michael J. O que o dinheiro não compra: os limites morais do mercado. Tradução de Clóvis Marques. Rio de Janeiro: Civilização Brasileira, 2012. p. 11.

${ }^{10}$ DUQUE, Marcelo Schenk. Direito privado e constituição: drittwirkung dos direitos fundamentais, construção de um modelo de convergência à luz dos contratos de consumo. São Paulo: Revista dos Tribunais, 2013 , p. 50.

${ }^{11}$ Sobre o tema, confira-se: RECASÉNS SICHES, Luis. Filosofia del derecho. México: Porrúa, 2008, p. 1-19; SARLET, Ingo Wolfgang. A eficácia dos direitos fundamentais: uma teoria geral dos direitos fundamentais na perspectiva constitucional. 10. ed. Porto Alegre: Livraria do Advogado, 2010, p. 79; COMPARATO, Fábio Konder. A afirmação histórica dos direitos humanos. 7. ed. São Paulo: Saraiva, 2010, p. 91-92; HUNT, Lynn. A
} 
no sistema jurídico brasileiro, só se admite a prática comercial e financeira que, além de outros princípios, respeite a dignidade da pessoa humana, que, em seu sentido mais amplo, congloba os direitos dos consumidores. Significa dizer que a norma constitucional procura compatibilizar a livre iniciativa com a tutela das pessoas vulneráveis expostas às práticas do mercado, utilizando o CDC como mecanismo para a instrumentalização dessa tutela. ${ }^{12}$

Assim, conforme exposto, o artigo $1^{\circ}$ do CDC expõe que a lei protetiva do consumidor é uma norma de interesse social, ou seja, é legislação que vai além da relação entre as partes (consumidor/fornecedor), pois também deve ser interpretado no interesse de toda a sociedade.

Noutros termos, o fornecedor que age contrariando o CDC não apenas viola o direito do consumidor diretamente envolvido, como também prejudica a livre concorrência e, em última análise, pode colocar outras pessoas em risco. ${ }^{13}$

Como 'coluna vertebral' do CDC, tem-se o artigo $4^{\circ}$ traça a Política Nacional de Relações de Consumo, que prevê os princípios mais importantes do código consumerista no intuito de cumprir essa função social supracitada. ${ }^{14}$ Destacadamente, o inciso I expresamente reconhece a vulnerabilidade do consumidor no mercado de consumo, razão pela qual se tem um microsssitema norteado por um 'código' (ao invés de simplesmente 'lei') ${ }^{15}$, que é expressamente protetivo. Com efeito, é em razão dessa vulnerabilidade que se busca, por meio da lei, promover o equilíbrio contratual, buscando soluções justas e harmônicas.

Além disso, é importante mencionar o artigo $6^{\circ}$ do Código, que prevê os direitos básicos dos consumidores. Em verdade, muitos direitos fundamentais expressos na Constituição surgem como direitos da personalidade no Código Civil ${ }^{16} \mathrm{e}$, na relação de consumo, são protegidos como direitos básicos. À guisa de exemplo, destaca-se a proteção à vida, à saúde e à segurança - mandamentos fundamentais - em todos os âmbitos do Direito.

\footnotetext{
invenção dos direitos humanos: uma história. Tradução de Rosaura Eichenberg. São Paulo: Cia. das Letras, 2009, p. 113-145.

${ }^{12}$ GARCIA, Leonardo de Medeiros. Código de Defesa do Consumidor comentado artigo por artigo. Salvador: Juspodivm, 2019, p. 25.

${ }^{13}$ Para ilustrar, destaca-se o consumidor por equiparação, vítima do evento, previsto no art. 17 do CDC. Neste caso, a pessoa protegida pelo código sequer possui relação jurídica com o fornecedor, sendo, mesmo assim, protegida pela lei. É o exemplo do celular defeituoso que explode e atinge pessoas que estavam próximas ao aparelho.

${ }^{14}$ GRAU. Eros Roberto. Interpretando o Código de Defesa do Consumidor. Revista de Direito do Consumidor, São Paulo: Revista dos Tribunais, v. 5, jan./mar. 1993, p. 166.

${ }^{15}$ DE LUCCA, Newton. Direito do consumidor: aspectos práticos - perguntas e respostas. São Paulo: Revista dos Tribunais, 1995 , p. 36-36.

${ }^{16}$ MORAES, Maria Celina Bodin de. Na medida da pessoa humana: estudos de direito civil-constitucional. Rio de Janeiro: Renovar, 2016, p. 85.
} 
Diante do exposto, para os fins do presente trabalho, é importante destacar a previsão do artigo $6^{\circ}$, inciso II, no qual consta como direito básico do consumidor a divulgação sobre o consumo adequado dos produtos e serviços, asseguradas a liberdade de escolha e a igualdade nas contratações.

Como se nota, visando evitar qualquer tipo de discriminação e como cumprimento dos objetivos fundamentais da Constituição, em especial o de promover o bem de todos, sem preconceitos de origem, raça, sexo, cor, idade e quaisquer outras formas de discriminação, o CDC consagrou como direitos básicos do consumidor a liberdade de escolha e a igualdade na aquisição de bens e serviços. Nesse sentido, vale lembrar, inclusive, o artigo $2^{\circ}$ da Declaração Universal de Direitos Humanos:

Não será também feita nenhuma distinção fundada na condição política, jurídica ou internacional do país ou território a que pertença uma pessoa, quer se trate de um território independente, sob tutela, sem governo próprio, quer sujeito a qualquer outra limitação de soberania. ${ }^{17}$

É dizer que, estando um produto ou serviço oferecido no mercado, é direito de qualquer consumidor efetuar a contratação deste, desde que esteja diposto a pagar o preço exigido. Em razão disso, a lei proibe que o fornecedor faça distinção de valores ou que realize ofertas contendo qualquer forma de discriminação, conforme expressamente prevê o CDC:

Art. 39. É vedado ao fornecedor de produtos ou serviços, dentre outras práticas abusivas:[...] [...] II - recusar atendimento às demandas dos consumidores, na exata medida de suas disponibilidades de estoque, e, ainda, de conformidade com os usos e costumes; [...] [...] IX - recusar a venda de bens ou a prestação de serviços, diretamente a quem se disponha a adquiri-los mediante pronto pagamento, ressalvados os casos de intermediação regulados em leis especiais. ${ }^{18}$

Conforme se nota, a própria norma consumerista somente permite a recusa nos casos excepcionais de intermediação regulados em leis especiais, como no caso de uma farmácia que nega a venda de um medicamento sem a apresentação da necessária prescrição médica. $\mathrm{E}$ tal proibição de discriminação é de tamanha importância jurídica que a recusa de venda de

\footnotetext{
${ }^{17}$ ORGANIZAÇÃO DAS NAÇÕES UNIDAS. Assembleia Geral das Nações Unidas. Declaração Universal dos Direitos Humanos. Paris. 10 dez. 1948. Disponível em: https://nacoesunidas.org/wpcontent/uploads/2018/10/DUDH.pdf. Acesso em: 15 jul. 2019.

${ }^{18}$ BRASIL. Lei no 8.078, de 11 de setembro de 1990. Código de Defesa do. Consumidor. Dispõe sobre a proteção do consumidor e dá outras providências. Disponível em: http://www.planalto.gov.br/ccivil_03/Leis/L8078.htm. Acesso em: 16 jul. 2019.
} 
bens e produtos oferecidos no mercado configura crime contra as relações de consumo, nos termos da Lei 8.137/90:

Art. $7^{\circ}$ Constitui crime contra as relações de consumo: I - favorecer ou preferir, sem justa causa, comprador ou freguês, ressalvados os sistemas de entrega ao consumo por intermédio de distribuidores ou revendedores; [...] [...] VI - sonegar insumos ou bens, recusando-se a vendê-los a quem pretenda comprá-los nas condições publicamente ofertadas, ou retê-los para o fim de especulação. ${ }^{19}$

Dessa maneira, o CDC se fundamenta na ideia de que a liberdade de escolha e a igualdade nas contratações devem ser respeitadas nas relações jurídicas de consumo, visando, evidentemente, consagrar uma sociedade plural mas, ao mesmo tempo, igualitária no que se refere ao exercício de direitos no mercado de consumo. Nesse contexto, salienta-se que a Internet é, verdadeiramente, um novo ambiente, no qual se faz presente uma nova espécie de consumidor (o "consumidor internauta"), demandando nova espécie de proteção normativa, para além do plano da economia tradicional, o que, segundo Pedro Modenesi, confere origem à figura do ciberconsumidor, "reconhecida pela maioria da doutrina que se dedica ao estudo da contratação eletrônica de consumo". ${ }^{20}$

Diante isso, é oportuno destacar que o CDC, embora não tenha regras específicas relacionadas às práticas de geopricing ou de geoblocking, é constituído de cláusulas gerais e princípios abrangentes que possibilitam a averiguação da ilicitude de tais práticas no mundo fático. Neste ponto, destaca-se que novos desafios surgem quando a proteção do consumidor é analisada no ambiente virtual. ${ }^{21}$ Com efeito, tais fenômenos exigem maior atenção e cuidado pelo sistema jurídico, em especial, visando à concretização dos direitos dos consumidores que se tornaram mais frágeis ao serem expostos à sociedade informatizada. ${ }^{22}$

\footnotetext{
${ }^{19}$ BRASIL. Lei $\mathrm{n}^{\circ} 8.137$, de 27 de dezembro de 1990. Define crimes contra a ordem tributária, econômica e contra as relações de consumo, e dá outras providências. Disponível em: http://www.planalto.gov.br/ccivil_03/leis/L8137.htm. Acesso em: 16 jul. 2019.

${ }^{20}$ MODENESI, Pedro. Contratos eletrônicos de consumo: aspectos doutrinário, legislativo e jurisprudencial. In: MARTINS, Guilherme Magalhães; LONGHI, João Victor Rozatti (Coords.). Direito digital: direito privado e Internet. 2. ed. Indaiatuba: Foco, 2019, p. 446.

${ }^{21}$ A despeito da multiplicidade de nomenclaturas, é fato que grande parte dos usuários da Internet está exposta à publicidade irrefreável, que dá origem à figura do 'turboconsumidor' descrito por Gilles Lipovetsky e Jean Serroy, na exata medida em que "o universo do consumo vê dissolver-se as antigas culturas de classe que enquadravam os comportamentos dos diferentes meios sociais por pressões e outras intimidações".

(LIPOVETSKY, Gilles; SERROY, Jean. A cultura-mundo: resposta a uma sociedade desorientada. Tradução de Maria Lúcia Machado. São Paulo: Cia. das Letras, 2011, p. 57.)

${ }^{22}$ MARQUES, Cláudia Lima. Confiança no comércio eletrônico e a proteção do consumidor. São Paulo: Revista dos Tribunais, 2004, p. 94.
} 


\section{O COMÉRCIO ELETRÔNICO E AS NOVAS PRÁTICAS DE DISCRIMINAÇÃO NO MERCADO}

Desde que se chegou à sociedade da informação, deflagrou-se a necessidade imediata de se repensar diversos institutos há tempos consagrados na sociedade, já que os seus impactos sobre direitos atinentes à privacidade, à liberdade e à autonomia, por exemplo, foram relativizados diante do poder de comunicação, de coleta e de processamento de dados proporcionado pelas tecnologias virtuais, ainda mais ao se considerar que a rede orienta-se cada vez mais para a criação de grandes grupos de poder. ${ }^{23}$

Em verdade, o uso da tecnologia abre novas dimensões para a exploração de práticas abusivas; porém, os dispositivos do CDC já são capazes de tutelá-las, ainda que se trate de uma lei datada de 1990. Significa que "a Internet configura um novo meio, permitindo a conexão de pessoas nas mais diversas situações, com os mais diversos propósitos. A interrelação é de tal modo facilitada que se costuma falar em desterritorialização das relações celebradas por meio eletrônico". ${ }^{24}$ Noutros dizeres, a proteção do consumidor poderá ser divida em "antes/depois" da aparição do comércio eletrônico, tornando necessárias novas soluções para esses novos problemas que surgem. ${ }^{25}$

Em verdade, é necessário deixar claro que o comércio eletrônico está conectado à ideia de economia digital e de economia da informação, de modo que é possível pensar que se está diante de um mundo novo, além do alcance regulatório do direito tradicionalmente concebido, porquanto alcançável por ações preditivas inovadoras, tais como: precificação baseada em análise comportamental ${ }^{26}$, framing e anchoring, adição de itens como presentes ou bônus, venda de itens em pacotes (bundling), fatiamento de preços etc. ${ }^{27}$ Em contraponto a isso, nunca se cogitou tanto de vigilância, conforme indicam Bauman e Lyon:

\footnotetext{
${ }^{23}$ PINHEIRO, Patrícia Peck. Proteção de dados pessoais: comentários à Lei n. 13.709/18 (LGPD). São Paulo: Saraiva, 2018, p. 13.

${ }^{24}$ KLEE, Antonia Espíndola Longoni. Comércio eletrônico. São Paulo: Revista dos Tribunais, 2014, p. 227.

${ }^{25}$ LORENZETTI, Ricardo Luís. Comércio eletrônico. Tradução de Fabiano Menke. São Paulo: Revista dos Tribunais, 2004, p. 354.

${ }^{26}$ Sobre o tema, confira-se: THALER, Richard H. Mental accounting matters. Journal of Behavioral Decision Making, Nova Jersey, v. 12, n. 3, p 183-206, jul. 1999; ARIELY, Dan; LOEWENSTEIN, George; PRELEC, Drazen. Coherent arbitrariness: stable demand curves without stable preferences. Quarterly Journal of Economics, Oxford, v. 118, n. 1, p. 73-106, fev. 2003.

${ }^{27}$ VAN BOOM, Willem H. Price intransparency, consumer decision making and European Consumer Law. Journal of Consumer Policy, Cham: Springer, v. 34, p. 359-376, 2011, p. 362-265.
} 
Os principais meios de obter segurança, ao que parece, são as novas técnicas e tecnologias de vigilância, que supostamente nos protegem, não de perigos distintos, mas de riscos nebulosos e informes. As coisas mudaram tanto para os vigilantes quanto para os vigiados. Se antes você podia dormir tranquilo sabendo que o vigia noturno estava no portão da cidade, o mesmo não pode ser dito da "segurança" atual. Ironicamente, parece que a segurança de hoje gera como subproduto - ou talvez, em alguns casos, como política deliberada? - certas formas de insegurança, uma insegurança fortemente sentida pelas pessoas muito pobres que as medidas de segurança deveriam proteger. ${ }^{28}$

E é neste contexto que surgem práticas abusivas exercidas no mercado, como aquelas denominadas de geoblocking e geopricing. A primeira é evidenciada pela manipulação da disponibilidade das ofertas. Em simples termos, a empresa promove o bloqueio de uma oferta a determinado grupo de consumidores, enquanto a disponibiliza para outros em razão da sua localização de conexão. Tal prática é viabilizada pelo uso da tecnologia na coleta (muitas vezes realizada por singles $(\text { licks })^{29}$ e interpretação dos dados, os quais permitem, por sua vez, a identificação da posição geográfica do consumidor/usuário.

Na segunda prática, denominada geopricing, o fornecedor, levando em consideração novamente a posição geográfica do consumidor, permitida também pela interpretação dos dados coletados, promove a diferenciação de preços. Dito de outro modo, por meio do geopricing a empresa pode apresentar, para o mesmo produto ou serviço, diversos preços, condicionando o valor à localização em que se encontra o usuário.

Desse modo, através do geoblocking e do geopricing, os fornecedores podem praticar total ou parcialmente a recusa à venda de bens ou à prestação de serviços, indicando tal discriminação a determinado grupo de consumidores geograficamente posicionados. Isto coloca em perspectiva o real valor da proteção de dados ${ }^{30}$, propiciando uma nova compreensão dos impactos que um mercado rico em dados (data-rich market) ${ }^{31}$ pode vir a ter sobre a própria estrutura econômica de um país.

\footnotetext{
${ }^{28}$ BAUMAN, Zygmunt; LYON, David. Vigilância líquida. Tradução de Carlos Alberto Medeiros. Rio de Janeiro: Zahar, 2013, p. 95-96.

${ }^{29}$ SANTOLIM, Cesar Viterbo Matos. Os princípios de proteção do consumidor e o comércio eletrônico no direito brasileiro. Revista de Direito do Consumidor, São Paulo: Revista dos Tribunais, v. 14, n. 55, p. 53-84, jul./set. 2005, p. 63.

${ }^{30}$ WINEGAR, Angela G.; SUNSTEIN, Cass R. How much is data privacy worth? A preliminary investigation. Journal of Consumer Policy, Cham: Springer, v. 42, p. 1-16, 2019, p. 3-5.

${ }^{31}$ MAYER-SCHÖNBERGER, Viktor; RAMGE, Thomas. Reinventing capitalism in the age of Big Data. Nova Iorque: Basic Books, 2018, p. 7. Anotam os autores: "The key difference between conventional markets and data-rich ones is the role of information flowing through them, and how it gets translated into decisions. In datarich markets we no longer have to condense our preferences into price and can abandon the oversimplification that was necessary because of communicative and cognitive limits. This makes it possible to pair decentralized decision-making, with its valuable qualities of robustness and resilience, with much-improved transactional efficiency."
} 
Evidentemente, conforme se salientou alhures, tais medidas configuram práticas abusivas, vedadas pelo CDC na esteira da dicção do artigo 39 do diploma. E, nas palavras de Fernanda Barbosa:

\begin{abstract}
Essas práticas abusivas levadas a efeito por fornecedores de produtos e serviços ao redor do mundo partem da discriminação entre consumidores em razão de sua origem (geodiscriminação), e acabam por gerar limitação ao livre trânsito de pessoas, com repercussão em outros direitos e garantias fundamentais, como o direito ao lazer e à cultura, sem falar do fortalecimento de preconceitos como resultado indireto, já que o convívio com diferentes indivíduos, grupos e culturas ainda se mostra a sua melhor forma de combate. ${ }^{32}$
\end{abstract}

Em verdade, antes mesmo do problema relacionado ao fato de a discriminação ocorrer, outra grande ilicitude presente está em ocultar do consumidor o uso dos seus dados para a prática do geopricing ou do geoblocking. ${ }^{33}$ Em observância ao direito básico do consumidor à informação, a empresa precisaria informar aos consumidores qual tipo de dado estaria sendo utilizado durante a navegação, visando ao cumprimento do dever de transparência.

Assim, é certo que o cerne do uso da localização geográfica pelos fornecedores tem seu centro de discussão na razoabilidade de uma possível diferenciação. Com efeito, destacase a possibilidade de os dados pessoais localizadores justificarem o tratamento distinto, de maneira legalmente tolerada. Se a diferenciação dos valores ocorrer, por exemplo, em razão do frete, não há que se falar em geodiscriminação e, consequentemente, não se configura nenhuma prática abusiva. Todavia, quando a geodiscriminação é utilizada no intuito de maximizar lucros, sem a devida 'justa causa', nas situações permitidas pelo CDC, configurarse-á evidente prática abusiva repudiável, que deve ser combatida pelo sistema jurídico.

\title{
5 OS METAPARÂMETROS DA LEI GERAL DE PROTEÇÃO DE DADOS PESSOAIS (LEI 13.709/2018) NA TUTELA DO CONSUMIDOR VIRTUAL
}

A Lei Geral de Proteção de Dados Pessoais (Lei no 13.709, de 14 de agosto de 2018, com redação consolidada pela Lei $n^{\circ} 13.853$, de 08 de julho de 2019), consagrou um dever geral em seu artigo 46, que trata do imperativo da segurança da informação. Em simples

\footnotetext{
${ }^{32}$ BARBOSA, Fernanda Nunes. O dano informativo do consumidor na era digital: uma abordagem a partir do reconhecimento do direito do consumidor como direito humano. Revista de Direito do Consumidor, São Paulo: Revista dos Tribunais, v. 122, p. 203-232, mar/abr. 2019, p. 213.

${ }^{33}$ DIAS, Daniel; NOGUEIRA, Rafaela; QUIRINO, Carina de Castro. Vedação à discriminação de preços sem justa causa: uma interpretação constitucional e útil do art. 39, X, do CDC. Revista de Direito do Consumidor, São Paulo: Revista dos Tribunais, v. 121, p. 51-97, jan./fev. 2019, p. 76.
} 
termos, o referido dispositivo estabeleceu a tutela da responsabilidade civil em razão de danos decorrentes da violação aos deveres de proteção da segurança dos dados, delimitando um critério geral de imputação lastreado na verificação e demonstração do defeito ${ }^{34}$ na prestação de serviços por parte dos provedores, com emanação lastreada na ruptura de uma expectativa legítima quanto à segurança dos processos de coleta, tratamento e armazenagem de dados.

Referida previsão encontra lastro comparativo no Regulamento Geral de Proteção de Dados europeu ${ }^{35}$, com destaque para a previsão de seu artigo $2^{\circ}$, que elenca como fundamentos o respeito à privacidade, a autodeterminação informativa, a liberdade de expressão, de informação, de comunicação e de opinião, a inviolabilidade da intimidade, da honra e da imagem, o direito ao livre desenvolvimento da personalidade, o desenvolvimento econômico e tecnológico, a livre iniciativa, a livre concorrência e a defesa do consumidor.

No direito brasileiro, quando se transcende a própria legislação para impor parâmetros preventivos (ou exigências de compliance), vê-se surgir vasto rol de novas nuances que somente quem está diretamente atrelado ao tratamento de dados poderá antever e evitar, o que atribui previsibilidade a certos riscos e demanda atuação conforme para o controle da responsabilização erigida pelo novo marco regulatório. ${ }^{36}$ Destarte, na linha do que já vem sinalizando a doutrina estrangeira, exige-se uma série de medidas de comprovação de boas práticas ${ }^{37}$ que, se presentes, moldarão o espectro de aferição da má conduta geradora de responsabilidade; trabalha-se, em termos de responsabilidade civil, com uma renovada função preventiva $^{38}$ que, com efeito, revela nítido alinhamento entre os modelos europeu e brasileiro:

\footnotetext{
${ }^{34}$ DRESCH, Rafael de Freitas Valle. Fundamentos da responsabilidade civil pelo fato do produto e do serviço: um debate jurídico-filosófico entre o formalismo e o funcionalismo no direito privado. Porto Alegre: Livraria do Advogado, 2009, p. 138. Comenta o autor: "a responsabilidade civil pelo fato do produto e do serviço no Código de Defesa do Consumidor é especial, fundada no defeito, o que, tecnicamente, determina a análise da culpa levíssima presumida".

${ }^{35}$ CASTRO, Catarina Sarmento e. Direito da informática, privacidade e dados pessoais. Coimbra: Almedina, 2005 , p. 229.

${ }^{36}$ BIONI, Bruno Ricardo. Proteção de dados pessoais: a função e os limites do consentimento. Rio de Janeiro. Forense, 2019, p 165.

37 JACKMAN, David. The compliance revolution: how compliance needs to change to survive. Nova Jersey: John Wiley \& Sons, 2015, p. 68. Destaca: "The embedding of corporate culture is a priority for compliance departments because a pro-compliance culture will deliver so many of the regulatory objectives, in theory, without too much intervention or cajoling by compliance."

${ }^{38}$ ROSENVALD, Nelson; OLIVEIRA, Fabrício de Souza. O ilícito na governança dos grupos de sociedades. Salvador: Juspodivm, 2019, p. 331. Destacam os autores: "O modelo jurídico da responsabilidade civil é por essência cambiante, extremamente sensível aos influxos econômicos e sociais. Na sociedade de riscos, um altivo papel do ordenamento jurídico consiste em induzir, de forma generalizada, comportamentos virtuosos, orientando potenciais ofensores a adotar medidas de segurança a evitar condutas danosas. Uma ode à virtude da 'previdência' (olhar antes).'
} 
Há grande semelhança quando se compara os direitos europeu e brasileiro sob esse ponto de vista. Afinal, a grande inovação que a LGPD operou no ordenamento jurídico brasileiro pode ser compreendida exatamente na instituição de um modelo ex-ante de proteção de dados.

Fundamenta-se esse conceito no fato de que não existem mais dados irrelevantes diante do processamento eletrônico e ubíquo de dados na sociedade da informação. Considerando que os dados pessoais são projeções diretas da personalidade, qualquer tratamento de dados acaba por influenciar a representação da pessoa na sociedade, podendo afetar sua personalidade e, portanto, tem o potencial de violar os seus direitos fundamentais. ${ }^{39}$

Nesse contexto específico, inúmeras ações podem (e devem) ser implementadas por quem detém o poder sobre os sistemas, a fim de se salvaguardar os riscos relacionados à proteção de dados dos usuários que se valem de um serviço específico para que haja lisura nas operações de tratamento. Práticas como a minimização do volume de processamento de dados pessoais (privacy by design) ${ }^{40}$, a anonimização ${ }^{41}$, a permissão de monitoramento do tratamento de dados pelo seu titular e até mesmo a realização de treinamentos regulares com as equipes são exemplos de ações que fomentam uma cultura de prevenção.

Nessa linha, é fundamental que se tenha em conta que toda política ou boa prática de governança de dados envolverá a articulação de algum objetivo independente e igualmente desejável por controladores e operadores de dados. Como consequência disso, a responsabilização pelo tratamento inadequado de dados pressuporá o equacionamento do enfrentamento das ações cabíveis e regularmente esperadas do respectivo agente para que seja possível promover o reequilíbrio das tensões causadas durante tais operações e que culminem na perda da autodeterminação informativa (ou, noutros dizeres, em verdadeira manipulação do controle exercido pelo consumidor sobre sua decisão). ${ }^{42}$

Mister realçar os dizeres de Ernest Weinrib, que destaca serem autônomos os objetivos aferidos como justificações independentes da lei de regência, às quais são aplicadas, e quanto

\footnotetext{
${ }^{39}$ BIONI, Bruno Ricardo; MENDES, Laura Schertel. Regulamento Europeu de Proteção de Dados Pessoais e a Lei Geral brasileira de Proteção de Dados: mapeando convergências na direção de um nível de equivalência. In: TEPEDINO, Gustavo; FRAZÃO, Ana; OLIVA, Milena Donato (Coords.). Lei Geral de Proteção de Dados Pessoais e suas repercussões no direito brasileiro. São: Paulo: Revista dos Tribunais, 2019, p. 810-811.

${ }^{40}$ NARAYANAN, Arvind; SHMATIKOV, Vitaly. Myths and fallacies of personally identifiable information. Communications of the ACM, Austin, v. 53, n. 6, p. 24-26, jun. 2010, p. 24.

${ }^{41}$ CAVOUKIAN, Ann; CASTRO, Daniel. Big Data and innovation, setting the record straight: de-identification does work. The Information Technology \& Innovation Foundation, Ontario, p. 1-18, jun. 2014, p. 1.

${ }^{42}$ WERTHEIN, Jorge. A sociedade da informação e seus desafios. Ciência da Informação, Brasília, v. 29, n. 2 , p. 71-77, mai./ago. 2000, p. 76. Comenta: “A perda do sentimento de controle sobre a própria vida e a perda da identidade são temas que continuam preocupantes e que estão ainda por merecer estratégias eficientes de intervenção."
} 
à independência entre umas e outras, para que possam representar impulsos normativos incompatíveis que precisam ser equilibrados. ${ }^{43}$

Em um período de "hiperhistoria", no qual o bem-estar dos indivíduos e das sociedades passou a depender inteiramente das Tecnologias de Informação e Comunicação (TICs) ${ }^{44}$, o papel de vetustos institutos jurídicos passa a ser revisitado para que direitos fundamentais possam ser preservados. $\mathrm{Na}$ Internet, sendo a privacidade o mais evidente desse rol de direitos, novos riscos por ela propiciados passam a demandar intervenções estruturais voltadas à sua prevenção, conforme salienta Helen Nissenbaum:

Temos um direito à privacidade, mas não se trata de um direito de controlar informações pessoais, ou de um direito de limitar o acesso a estas informações. Em vez disso, é o direito de viver em um mundo no qual nossas expectativas sobre o fluxo de informações pessoais são, na maioria das vezes, atendidas; expectativas que são moldadas não apenas pela força do hábito e pelas convenções, mas devido a uma confiança geral no apoio mútuo que esses fluxos concedem aos princípios-chave de organização da vida social, incluindo os princípios morais e políticos. Esse é o direito que chamei de integridade contextual, alcançada através do equilíbrio harmonioso de regras sociais, ou normas, com valores, fins e propósitos locais e gerais. Isso nunca é uma harmonia estática, no entanto, porque, com o tempo, as condições mudam e os contextos e normas evoluem junto com eles. ${ }^{45}$

Na mesma medida em que o Estado passa por densa reformulação para se tornar capaz de atender às demandas inauguradas pela nova era comunicacional, os deveres de proteção

\footnotetext{
${ }^{43}$ WEINRIB, Ernest J. The disintegration of duty. In: MADDEN, M. Stuart (Ed.). Exploring tort law. Cambridge: Cambridge University Press, 2005, p. 177-178. O autor ainda comenta: "In these circumstances there can only be different specific kinds of duty, with each kind representing the particular policies or the particular balance among policies that are recognized as decisive in situations of that sort. Moreover, the conception of duty is inwardly fragmented into the various policies that favor one party or the other. The duty issue is therefore seen as the locus not for defining the wrong identically from the standpoint of both parties, but for forwarding or balancing policies that rest on considerations that apply differently to each of them."

${ }^{44}$ BUCKLAND, Michael. Information and society. Cambridge: The MIT Press, 2017, p. 51. Comenta: "Sensing significant developments in one's environment and seeking to influence others-becoming informed and informing others - are basic to survival. In human societies, these interactions are largely and increasingly achieved through documents. When we speak of a community knowing something, it commonly means that some of the individuals in a community know something. The ability to influence what is known within a group can have important political, economic, and practical consequences. What people know is a constituent part of their culture and knowing, believing, and understanding always occurs within a cultural context. In this way, information always has physical, mental, and social aspects that can never be fully separated."

${ }^{45}$ NISSENBAUM, Helen. Privacy in context: technology, policy, and the integrity of social life. Stanford: Stanford University Press, 2010, p. 231, tradução livre. No original: "We have a right to privacy, but it is neither a right to control personal information nor a right to have access to this information restricted. Instead, it is a right to live in a world in which our expectations about the flow of personal information are, for the most part, met; expectations that are shaped not only by force of habit and convention but a general confidence in the mutual support these flows accord to key organizing principles of social life, including moral and political ones. This is the right I have called contextual integrity, achieved through the harmonious balance of social rules, or norms, with both local and general values, ends, and purposes. This is never a static harmony, however, because over time, conditions change and contexts and norms evolve along with them."
} 
que lhe são impostos constitucionalmente, com direcionamento especialmente voltado à vedação da proteção insuficiente ${ }^{46}$ - cenário desafiador em uma sociedade marcada pela coleta e pelo fluxo massivo de dados e pela interoperabilidade sistêmica em tempo real - de maior relevo será a imposição dos parâmetros de prevenção às corporações que, essencialmente, trabalhem com o novo substrato da economia digital: a informação.

$\mathrm{Na}$ esfera pré-contratual, a lisura e a transparência são esperadas como desdobramentos da boa-fé objetiva que rege as relações de consumo e pela qual se permite integrar a norma jurídica para a junção do dever de proteção de dados emanado da LGPD aos deveres de respeito à boa-fé objetiva e à proteção das relações de consumo já delimitados como standards normativo-comportamentais no Código de Defesa do Consumidor. ${ }^{47}$ Isso porque "os fornecedores que conduzem negócios por meio eletrônico na Internet devem esclarecer como coletam e usam os dados dos consumidores, em face do direito de informação por estes titularizado (art. 6º, III, da Lei 8.078/1990)". ${ }^{48}$

Nesse plano, considerando-se que a proteção da privacidade demanda a implementação de vasto rol de boas práticas que se traduzem, ao fim e ao cabo, no imperativo da prevenção imponíveis às corporações que explorem atividades voltadas a tais mercados e que, tradicionalmente - por serem detentoras do controle de arquitetura e programação das plataformas onde se operam tais transações - acabam por se sobrepujar ao animus regulatório e fiscalizatório de um Estado particularmente frágil, "no qual os mecanismos de controles de preços são mefistolicamente exercidos pelos oligopólios; no qual a sedução exercida pela publicidade e pelo marketing agressivo ultrapassa os limites do inverossímil (...)". ${ }^{49}$

Para combater essa situação, não se pode admitir a adoção abusiva de práticas discriminatórias na Internet, que impedem até mesmo a concretização de direitos humanos já consolidados, conforme alerta a doutrina:

\footnotetext{
${ }^{46}$ SILVA, Jorge Pereira da. Deveres do Estado de protecção de direitos fundamentais: fundamentação e estrutura das relações jusfundamentais triangulares. 3. ed. Lisboa: Universidade Católica Editora, 2015, p. 585.

${ }^{47}$ MARQUES, Claudia Lima. Contratos no Código de Defesa do Consumidor. 8. ed. São Paulo: Revista dos Tribunais, 2016, p. 810; MIRAGEM, Bruno. Função social do contrato, boa-fé e bons costumes: nova crise dos contratos e a reconstrução da autonomia negocial pela concretização das cláusulas gerais. In: MARQUES, Claudia Lima (Org.). A nova crise do contrato. São Paulo: Revista dos Tribunais, 2007, p. 176-200.

${ }^{48}$ MARTINS, Guilherme Magalhães. Responsabilidade civil por acidente de consumo na Internet. 2. ed. São Paulo: Revista dos Tribunais, 2014, p. 334.

${ }^{49}$ DE LUCCA, Newton. A proteção dos consumidores no âmbito da internet. In: LIMA, Cíntia Rosa Pereira de; NUNES, Lydia Neves Bastos Telles (Coords.). Estudos avançados de direito digital. Rio de Janeiro: Elsevier, 2014, p. 97.
} 
Nenhum outro direito humano pode ser reivindicado se o princípio de nãodiscriminação não for aplicado. A não-discriminação é o princípio que torna os outros direitos operacionais e, em certo sentido, torna os direitos humanos universais, não apenas no discurso jurídico, mas também, em grande parte, no discurso político e moral. A Declaração de Princípios da WSIS e o Plano de Ação para o desenvolvimento de uma sociedade global da informação, embora apenas documentos políticos com os quais os Estados se comprometeram, servem como plataformas a partir das quais o desenvolvimento da sociedade global da informação deve ocorrer. Os documentos sinalizam a importância da sociedade da informação, e tal sociedade não pode existir como uma democracia se o princípio da não-discriminação não for aplicado. Os documentos devem lembrar os Estados de suas obrigações de combater a discriminação e recomendar a implementação e integração do princípio da nãodiscriminação na legislação e de políticas nacionais para proteger os indivíduos contra violações de direitos humanos e garantir seus direitos de acesso às TICs. A sociedade da informação só se tornará realidade quando todos os seres humanos puderem reivindicar seus direitos sem preconceito e discriminação. ${ }^{50}$

Assim, quando se perquire os meandros e limites da concretização de deveres de prevenção para a tutela das relações jurídicas de consumo na Internet, imperiosa será a incidência de deveres de governança como resposta à dificuldade de tutela dessa nova realidade $^{51}$, que ultrapassa a ideia de segurança da informação como mera utilização de bloqueios que evitem a invasão e o vazamento de dados ${ }^{52}$, pois o que se almeja é chegar a um contexto de completa e verdadeira delimitação de métodos preventivos capazes de propagar uma cultura de integridade (compliance), transparência (disclosure) e responsabilidade (accountability).

\footnotetext{
${ }^{50}$ ZARREHPARVAR, Mandana. A nondiscriminatory information society. In: JØRGENSEN, Rikke Frank (Ed.). Human rights in the global information society. Cambridge: The MIT Press, 2006, p. 233, tradução livre. No original: "No other human rights can be claimed if the nondiscrimination principle is not applied. Nondiscrimination is the principle that makes the other rights operational and, in a sense, makes human rights universal, not only in judicial discourse but also, to a great degree, in political and moral discourse. The WSIS Declaration of Principles and the Action Plan for the development of a global information society, although only political documents that state parties have committed themselves to, serve as platforms from which the development of the global information society should occur. The documents signal the importance of the information society, and such a society cannot exist as a democratic one if the principle of nondiscrimination is not applied. The documents ought to remind the states of their obligations to combat discrimination and to recommend implementation and mainstreaming of the non-discrimination principle in national legislation and policies to protect individuals from violations of human rights and secure their rights to access ICT. The information society can become a reality only when all human beings can claim their rights without prejudice and discrimination."

${ }^{51}$ PÉREZ LUÑO, Antonio Enrique. Manual de informática e derecho. Barcelona: Ariel, 1996, p. 10 et seg.

${ }^{52}$ SIMÃO FILHO, Adalberto. Dano ao consumidor por invasão do site ou da rede. In: DE LUCCA, Newton; SIMÃO FILHO, Adalberto (Coords.). Direito \& Internet: aspectos jurídicos relevantes. São Paulo: Edipro, 2001, p. 103.
} 


\section{CONCLUSÃO}

Por todo o mencionado, mesmo admitindo que muitas questões relevantes sobre o tema ultrapassam o contexto do presente trabalho, certamente a decisão envolvendo a "Decolar.com" serve como um alerta de que a ocorrência de práticas abusivas no comércio eletrônico brasileiro não configura um universo de impunidade inacessível e intutelável pelo labor estatal, uma vez que se encaixa como um importante referencial para a ampliação dos debates sobre o tema - crucial para o atual contexto social de consumo.

A investigação deflagrada pelo Ministério Público do Estado do Rio de Janeiro desencadeou apurações que já resultaram em sanção administrativa e, eventualmente, podem vir a resultar em responsabilidade civil da empresa em questão. Para além disso, obtempera-se a existência de regulação aplicável a este caso e a outros assemelhados, mesmo antes da vigência da Lei Geral de Proteção de Dados Pessoais, ainda em vacatio legis.

Em nítido escorço de reafirmação do campo de proteção de direitos fundamentais, atribui-se realce ao papel do Código de Defesa do Consumidor como eixo de um microssistema que ultrapassa as lindes das tradicionais relações de consumo e irradia seus efeitos sobre as relações virtuais, ganhando contornos peculiares que, embora possam (e devam) ser melhor trabalhados na legislação específica, já permitem a imposição de sanções voltadas a coibir práticas espúrias.

Destaca-se, finalmente, que a predição comportamental a partir de algoritmos desafia o jus imperii estatal, uma vez que o controle sobre as plataformas resta, ao fim e ao cabo, sob o poder das corporações que delas se valem para impor métricas dedicadas à otimização de seus resultados comerciais. Nessa linha, a proliferação de uma cultura de prevenção, baseada em uma função revigorante da responsabilidade civil catalisada por instrumentais ex ante, aparece como um saudável novo filtro para a imposição de deveres que fazem ressurgir a teoria do risco, sob viés aprimorado e adequado à sociedade da informação.

Sem dúvidas, com a vigência da Lei Geral de Proteção de Dados Pessoais, o Brasil passará a contar com vasto rol de novos mecanismos que poderão ser impostos a quem atue com a coleta, o tratamento e a armazenagem de dados a fim de prevenir, objetivamente, danos passíveis de responsabilização. Com a esperada efetivação dos deveres de proteção contidos no texto constitucional, espera-se atuação estatal condizente não apenas com o labor legiferante, mas também com o papel fiscalizatório e sancionador do desrespeito aos 
imperativos de segurança da informação, proteção à privacidade e de resguardo dos dados pessoais.

\section{REFERÊNCIAS}

ARIELY, Dan; LOEWENSTEIN, George; PRELEC, Drazen. Coherent arbitrariness: stable demand curves without stable preferences. Quarterly Journal of Economics, Oxford, v. 118, n. 1, p. 73-106, fev. 2003.

BARBOSA, Fernanda Nunes. O dano informativo do consumidor na era digital: uma abordagem a partir do reconhecimento do direito do consumidor como direito humano. Revista de Direito do Consumidor, São Paulo: Revista dos Tribunais, v. 122, p. 203-232, mar/abr. 2019.

BAUMAN, Zygmunt; LYON, David. Vigilância líquida. Tradução de Carlos Alberto Medeiros. Rio de Janeiro: Zahar, 2013.

BENJAMIN, Antonio Herman V.; MARQUES, Claudia Lima; BESSA, Leonardo Roscoe. Manual de direito do consumidor. 7. ed. São Paulo: Revista dos Tribunais, 2016.

BIONI, Bruno Ricardo. Proteção de dados pessoais: a função e os limites do consentimento. Rio de Janeiro. Forense, 2019.

BIONI, Bruno Ricardo; MENDES, Laura Schertel. Regulamento Europeu de Proteção de Dados Pessoais e a Lei Geral brasileira de Proteção de Dados: mapeando convergências na direção de um nível de equivalência. In: TEPEDINO, Gustavo; FRAZÃO, Ana; OLIVA, Milena Donato (Coords.). Lei Geral de Proteção de Dados Pessoais e suas repercussões no direito brasileiro. São: Paulo: Revista dos Tribunais, 2019.

BRASIL. Lei no 8.078, de 11 de setembro de 1990. Código de Defesa do. Consumidor. Dispõe sobre a proteção do consumidor e dá outras providências. Disponível em: http://www.planalto.gov.br/ccivil_03/Leis/L8078.htm. Acesso em: 16 jul. 2019.

BRASIL. Lei $\mathrm{n}^{\circ} 8.137$, de 27 de dezembro de 1990. Define crimes contra a ordem tributária, econômica e contra as relações de consumo, e dá outras providências. Disponível em: http://www.planalto.gov.br/ccivil_03/leis/L8137.htm. Acesso em: 16 jul. 2019.

BRASIL. Lei no 13.709, de 14 de agosto de 2018. Lei Geral de Proteção de Dados Pessoais. Disponível em: http://www.planalto.gov.br/ccivil_03/_Ato2015-2018/2018/Lei/L13709.htm. Acesso em: 08 jul. 2019.

BRASIL. Ministério da Justiça e Segurança Pública. Decolar.com é multada por prática de geo pricing e geo blocking. Disponível em: https://www.justica.gov.br/news/collective-nitfcontent-51. Acesso em 11 jul. 2019.

BRASIL. Secretaria Nacional do Consumidor. Departamento Nacional de Proteção e Defesa do Consumidor. Despacho $n^{o}$ 299/2018. Decisão de Aplicação de Sanção Administrativa. 
Processo $n^{\circ}$ 08012.002116/2016-21. Representada: Decolar.com Ltda. DOU. Diário Oficial da União. Publicado no DOU de 18 de junho 06 de 2018.

BUCKLAND, Michael. Information and society. Cambridge: The MIT Press, 2017.

CANARIS, Claus-Wilhelm. Direitos fundamentais e direito privado. Tradução de Ingo Wolfgang Sarlet e Paulo Mota Pinto. Coimba: Almedina, 2003.

CASTRO, Catarina Sarmento e. Direito da informática, privacidade e dados pessoais. Coimbra: Almedina, 2005.

CAVOUKIAN, Ann; CASTRO, Daniel. Big Data and innovation, setting the record straight: de-identification does work. The Information Technology \& Innovation Foundation, Ontario, p. 1-18, jun. 2014.

COMPARATO, Fábio Konder. A afirmação histórica dos direitos humanos. 7. ed. São Paulo: Saraiva, 2010.

COSTA, Daiane. Decolar recebe pedido de reparação de $\mathrm{R} \$ 57$ milhões por cobrar mais de brasileiros. $O$ Globo. 08 fev. 2018. Disponível em: https://oglobo.globo.com/economia/decolar-recebe-pedido-de-reparacao-de-57-milhoes-porcobrar-mais-de-brasileiros-22367398. Acesso em: 04 ago. 2019.

DE LUCCA, Newton. A proteção dos consumidores no âmbito da internet. In: LIMA, Cíntia Rosa Pereira de; NUNES, Lydia Neves Bastos Telles (Coords.). Estudos avançados de direito digital. Rio de Janeiro: Elsevier, 2014.

DE LUCCA, Newton. Direito do consumidor: aspectos práticos - perguntas e respostas. São Paulo: Revista dos Tribunais, 1995.

DIAS, Daniel; NOGUEIRA, Rafaela; QUIRINO, Carina de Castro. Vedação à discriminação de preços sem justa causa: uma interpretação constitucional e útil do art. 39, X, do CDC. Revista de Direito do Consumidor, São Paulo: Revista dos Tribunais, v. 121, p. 51-97, jan./fev. 2019.

DRESCH, Rafael de Freitas Valle. Fundamentos da responsabilidade civil pelo fato do produto e do serviço: um debate jurídico-filosófico entre o formalismo e o funcionalismo no direito privado. Porto Alegre: Livraria do Advogado, 2009.

DUQUE, Marcelo Schenk. Direito privado e constituição: drittwirkung dos direitos fundamentais, construção de um modelo de convergência à luz dos contratos de consumo. São Paulo: Revista dos Tribunais, 2013.

GARCIA, Leonardo de Medeiros. Código de Defesa do Consumidor comentado artigo por artigo. Salvador: Juspodivm, 2019.

GRAU. Eros Roberto. Interpretando o Código de Defesa do Consumidor. Revista de Direito do Consumidor, São Paulo: Revista dos Tribunais, v. 5, jan./mar. 1993. 
HUNT, Lynn. A invenção dos direitos humanos: uma história. Tradução de Rosaura Eichenberg. São Paulo: Cia. das Letras, 2009.

JACKMAN, David. The compliance revolution: how compliance needs to change to survive. Nova Jersey: John Wiley \& Sons, 2015.

KLEE, Antonia Espíndola Longoni. Comércio eletrônico. São Paulo: Revista dos Tribunais, 2014.

LIMBERGER, Têmis. Direito e informática: o desafio de proteger os direitos do cidadão. In: SARLET, Ingo Wolfgang (Org.). Direitos fundamentais, informática e comunicação: algumas aproximações. Porto Alegre: Livraria do Advogado, 2007.

LIPOVETSKY, Gilles; SERROY, Jean. A cultura-mundo: resposta a uma sociedade desorientada. Tradução de Maria Lúcia Machado. São Paulo: Cia. das Letras, 2011.

LORENZETTI, Ricardo Luís. Comércio eletrônico. Tradução de Fabiano Menke. São Paulo: Revista dos Tribunais, 2004.

MARQUES, Cláudia Lima. Confiança no comércio eletrônico e a proteção do consumidor. São Paulo: Revista dos Tribunais, 2004.

MARQUES, Claudia Lima. Contratos no Código de Defesa do Consumidor. 8. ed. São Paulo: Revista dos Tribunais, 2016.

MARTINS, Guilherme Magalhães. Responsabilidade civil por acidente de consumo na Internet. 2. ed. São Paulo: Revista dos Tribunais, 2014.

MAYER-SCHÖNBERGER, Viktor; RAMGE, Thomas. Reinventing capitalism in the age of Big Data. Nova Iorque: Basic Books, 2018.

MIOZZO, Júlia. Decolar é multada em R \$ 7,5 milhões por práticas abusivas contra consumidor. InfoMoney. 18 jun. 2018. Disponível em: https://www.infomoney.com.br/minhasfinancas/turismo/noticia/7479979/decolar-multada-milhoes-por-praticas-abusivas-contraconsumidor. Acesso em: 12 jul. 2019.

MIRAGEM, Bruno. Função social do contrato, boa-fé e bons costumes: nova crise dos contratos e a reconstrução da autonomia negocial pela concretização das cláusulas gerais. In: MARQUES, Claudia Lima (Org.). A nova crise do contrato. São Paulo: Revista dos Tribunais, 2007.

MODENESI, Pedro. Contratos eletrônicos de consumo: aspectos doutrinário, legislativo e jurisprudencial. In: MARTINS, Guilherme Magalhães; LONGHI, João Victor Rozatti (Coords.). Direito digital: direito privado e Internet. 2. ed. Indaiatuba: Foco, 2019.

MORAES, Maria Celina Bodin de. Na medida da pessoa humana: estudos de direito civilconstitucional. Rio de Janeiro: Renovar, 2016. 
NARAYANAN, Arvind; SHMATIKOV, Vitaly. Myths and fallacies of personally identifiable information. Communications of the ACM, Austin, v. 53, n. 6, p. 24-26, jun. 2010.

NISSENBAUM, Helen. Privacy in context: technology, policy, and the integrity of social life. Stanford: Stanford University Press, 2010.

ORGANIZAÇÃO DAS NAÇÕES UNIDAS. Assembleia Geral das Nações Unidas. Declaração Universal dos Direitos Humanos. Paris. 10 dez. 1948. Disponível em: https://nacoesunidas.org/wp-content/uploads/2018/10/DUDH.pdf. Acesso em: 15 jul. 2019.

PÉREZ LUÑO, Antonio Enrique. Manual de informática e derecho. Barcelona: Ariel, 1996.

PINHEIRO, Patrícia Peck. Proteção de dados pessoais: comentários à Lei n. 13.709/18 (LGPD). São Paulo: Saraiva, 2018.

RECASÉNS SICHES, Luis. Filosofia del derecho. México: Porrúa, 2008.

RIBEIRO, Luci. Decolar é multada em R \$ 7,5 milhões por práticas abusivas. Estadão. 18 jun. 2018. Disponível em: https://economia.estadao.com.br/noticias/negocios,decolar-e-multadaem-r-7-5-milhoes-por-praticas-abusivas,70002354803. Acesso em 11 de jul. de 2019.

ROSENVALD, Nelson; OLIVEIRA, Fabrício de Souza. O ilícito na governança dos grupos de sociedades. Salvador: Juspodivm, 2019.

SANDEL, Michael J. O que o dinheiro não compra: os limites morais do mercado. Tradução de Clóvis Marques. Rio de Janeiro: Civilização Brasileira, 2012.

SANTOLIM, Cesar Viterbo Matos. Os princípios de proteção do consumidor e o comércio eletrônico no direito brasileiro. Revista de Direito do Consumidor, São Paulo: Revista dos Tribunais, v. 14, n. 55, p. 53-84, jul./set. 2005.

SARLET, Ingo Wolfgang. A eficácia dos direitos fundamentais: uma teoria geral dos direitos fundamentais na perspectiva constitucional. 10. ed. Porto Alegre: Livraria do Advogado, 2010.

SILVA, Jorge Pereira da. Deveres do Estado de protecção de direitos fundamentais: fundamentação e estrutura das relações jusfundamentais triangulares. 3. ed. Lisboa: Universidade Católica Editora, 2015.

SIMÃO FILHO, Adalberto. Dano ao consumidor por invasão do site ou da rede. In: DE LUCCA, Newton; SIMÃO FILHO, Adalberto (Coords.). Direito \& Internet: aspectos jurídicos relevantes. São Paulo: Edipro, 2001.

THALER, Richard H. Mental accounting matters. Journal of Behavioral Decision Making, Nova Jersey, v. 12, n. 3, p 183-206, jul. 1999.

VAN BOOM, Willem H. Price intransparency, consumer decision making and European Consumer Law. Journal of Consumer Policy, Cham: Springer, v. 34, p. 359-376, 2011. 
VENTURA, Ivan. Decolar.com é multada em $R \$ 7,5$ milhões por desrespeito ao consumidor. Consumidor Moderno. 18 jun. 2018. Disponível em: https://www.consumidormoderno.com.br/2018/06/18/decolar-multada-milhoes-desrespeitoconsumidor/. Acesso em: 11. jul 2019.

WEINRIB, Ernest J. The disintegration of duty. In: MADDEN, M. Stuart (Ed.). Exploring tort law. Cambridge: Cambridge University Press, 2005.

WERTHEIN, Jorge. A sociedade da informação e seus desafios. Ciência da Informação, Brasília, v. 29, n. 2, p. 71-77, mai./ago. 2000.

WINEGAR, Angela G.; SUNSTEIN, Cass R. How much is data privacy worth? A preliminary investigation. Journal of Consumer Policy, Cham: Springer, v. 42, p. 1-16, 2019.

ZARREHPARVAR, Mandana. A nondiscriminatory information society. In: JØRGENSEN, Rikke Frank (Ed.). Human rights in the global information society. Cambridge: The MIT Press, 2006.

\section{DADOS DA PUBLICAÇÃO}

Categoria: artigo submetido ao double-blind review.

Recebido em: 05/08/2019.

Aceito em: 17/07/2020 


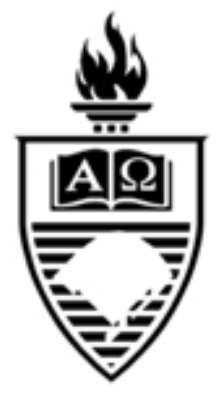

